\title{
Postharvest Factors Governing the Development of Peteca Rind Pitting on 'Meyer' Lemons
}

\author{
B.L. Wild \\ New South Wales Agriculture and Fisheries, Gosford, Horticultural \\ Postharvest Laboratory, P. O. Box 355, Gosford 22.50, Australia \\ Additional index words. degreening, ethylene, rumple, storage, temperature, wax, Citnus \\ meyeri
}

\begin{abstract}
The postharvest development of peteca rind pitting in 'Meyer' lemons [Citrus meyeri (Y.) Tan] was aggravated by citrus wax application and fruit brushing. Increasing brushing time increased the incidence of the disorder. Polyethylene-based waxes induced more peteca than carnauba-based wax formulations. Ethylene degreening and/ or storage before waxing decreased fruit susceptibility, while application of the fungicide guazatine did not increase peteca incidence. Storage between 10 and $25 \mathrm{C}$ had no effect on injury levels. Chemical name used: bis(8-guanidino-octyl) amine (guazatine).
\end{abstract}

Severe, deep rind pitting of 'Meyer' lemons was experienced in 1987 with crops grown in southeastern Queensland, Australia. The disorder developed 3 to 4 days after fruit had been packed and marketed. Investigators identified the symptoms as "peteca", as described by Fawcett and Lee (1926). This disorder of lemons also has been described as "rumple" (Chapot and Bachcecioglu, 1969; Knorr, 1963). Its occurrence in 'Meyer' lemons, however, had not been considered a problem up to this time (Knorr and Koo, 1969).

Several factors have been shown to affect the incidence of this disorder. Large, mature fruit are more susceptible than small, immature fruit (Grierson, 1981; Knorr and Koo, 1969). Tree position was also shown to be important, with fruit on the east side being

Received for publication 18 June 1990. 1 wish to acknowledge K.R. Ward for assistance in this project and D.R. Harris for help with the statistical analysis. I also acknowledge A. Jenkins of Golden Mile Holdings, Beerwah, Queensland, for supplying fruit.

'Special Research Horticulturist. the most susceptible (Salerno, 1963). Mineral nutrition, particularly relating to $\mathrm{Ca}$ and $\mathrm{B}$ metabolism, also pays a role in the development of the disorder (Khalidy et al., 1969). The disorder can occur with mature fruit on the tree and can also develop after the fruit have been harvested (Oberbacher and Knorr, 1965; Offers, 1987).

This paper reports on experiments that studied the effects of ethylene degreening, application of the fungicide guazatine, brushing time, storage temperature, and waxing on subsequent peteca development in 'Meyer' lemons.

'Meyer' lemons were obtained from the Beerwah area in southeastern Queensland, Australia. Fruit were carefully clipped from the trees in Jan. 1988 and transported overnight in nonrefrigerated (range 18 to $25 \mathrm{C}$ ) trucks to Gosford. On arrival at the laboratory, the lemons were randomized into treatment units according to the experiments being conducted.

Ethylene, fungicide, and waxing (Expt. 1). A three-way factorial experiment testing the effects of ethylene degreening, the fungicide guazatine (Panoctine $40 \%$ a.i., Shell Chem- 


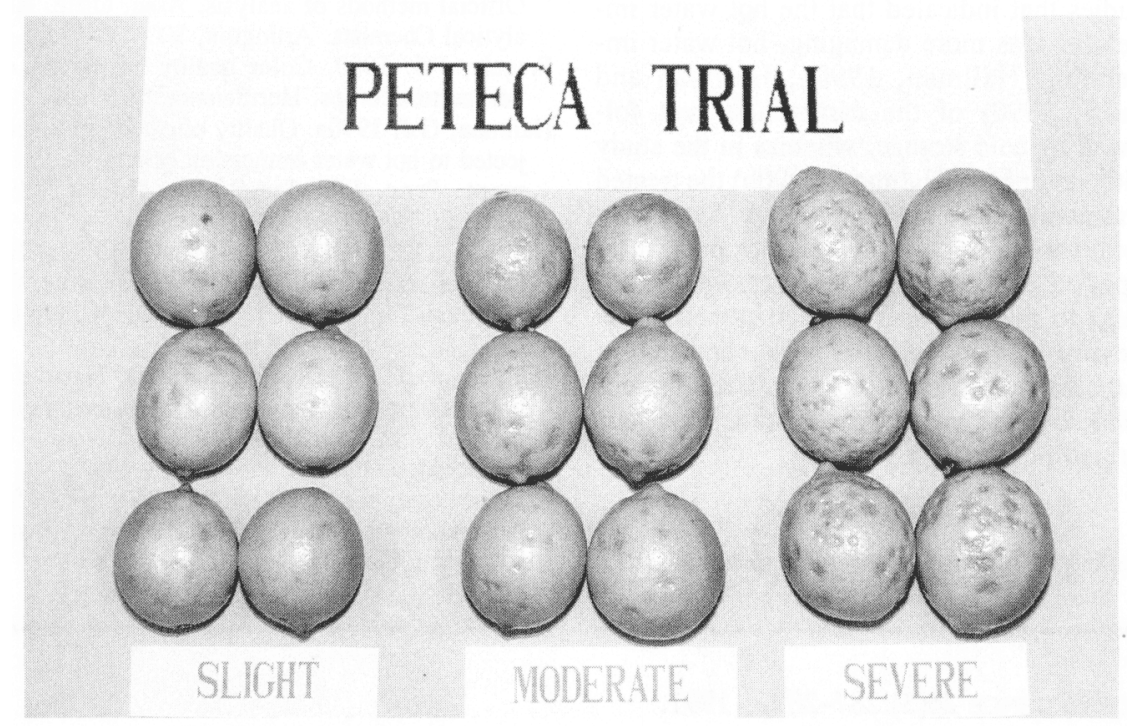

Fig. 1. Categories of peteca rind pitting used to assess the effect of various postharvest treatments on its development in 'Meyer' lemons.

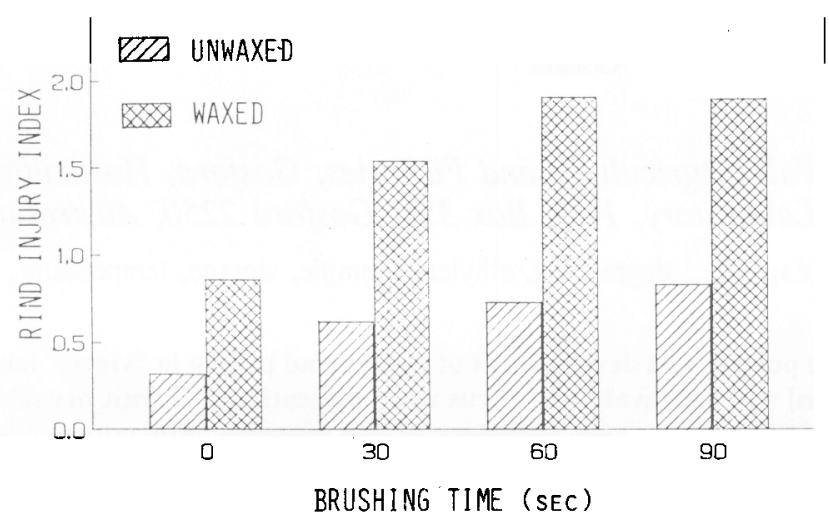

Fig. 2. Effect of increasing brushing times and wax application on peteca development in 'Meyer' lemons. See Table 3 for analysis of variance.

Table 1. Analysis of variance of the effects of fungicide application, ethylene, and waxing on peteca development in 'Mever' lemons.

\begin{tabular}{lccc}
\hline Source & df & Mean squares & F \\
Fungicide (Fung) & 1 & 0.0006 & $0.3^{\text {Ns }}$ \\
Wax & 1 & 0.3246 & $190.9^{* * *}$ \\
Ethylene (Ethyl) & 1 & 0.1999 & $117.6^{* * *}$ \\
Fung $\times$ wax & 1 & 0.0000 & $0.0^{\text {Ns }}$ \\
Fung $\times$ ethyl & 1 & 0.0003 & $0.2^{\text {Ns }}$ \\
Wax $\times$ ethyl & 1 & 0.0836 & $49.2^{* * *}$ \\
Fung $\times$ wax $\times$ ethyl & 1 & 0.0032 & $1.9^{\text {Ns }}$ \\
Pooled residual & 24 & 0.0017 & \\
\hline
\end{tabular}

Ns,***Not significant at $P>0.05$ or significant at $P<0.001$, respectively.

Table 2. Effects of fungicide application, ethylene degreening, and waxing on peteca development in lemons. See Table 1 for analysis of variance.

\begin{tabular}{lcccc}
\hline & \multicolumn{4}{c}{ Peteca development } \\
\cline { 2 - 4 } Fungicide & \multicolumn{2}{c}{ No wax } & Waxed \\
\cline { 2 - 5 } Control & No ethylene & Ethylene & No ethylene & Ethylene \\
Guazatine & 0.24 & 0.15 & 1.58 & 0.38 \\
& 0.28 & 0.06 & 1.49 & 0.39
\end{tabular}

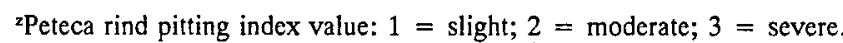

icals, Australia), and waxing was conducted using eight treatment units, each containing 40 fruits. One-half of the treatment units was dipped for $30 \mathrm{sec}$ in guazatine at 500 $\mathrm{mg} \cdot 1$ iter $^{-1}$ and the other half in water.

Half of each group was then treated with
$50 \mu \mathrm{l}$ ethylene/liter according to the "shot" method described by Hail et al. (1968). This procedure involves the venting and recharging of the chamber every $8 \mathrm{~h}$ to prevent $\mathrm{CO}_{2}$ accumulation. Degreening continued for 3 days in a sealed 280-liter galvanized iron chamber at $25 \mathrm{C}$. The other half of the treatment units were stored under the same conditions but without the ethylene treatment. At the end of this time, half of each group was dipped in a commercial polyethylenebased citrus wax containing $16 \%$ solids (Britseal, Milestone Chemicals, Australia) and the rest remained untreated.

Fruit were rated for rind pitting after 4 days of storage under ambient temperatures and sorted into four groups according to the number of pits per fruit: $0=$ no rind pitting; $1=$ slight symptoms (less than five pits per fruit) $; 2=$ moderate symptoms ( pits); 3 = severe (>20 pits) (Fig. 1).

An injury index was then determined by: index $=\sum$ (number of fruit in rating category $\times$ rating category)/number of fruit in sample. Log-transformed data were tested by analysis of variance as a $2 \times 2 \times 2$ factorial trial, replicated four times. Significant differences between means were determined by using LSD, calculated at $P=0.01$.

Brushing and wax (Expt. 2). A two-way factorial experiment was conducted examining brushing time effects and wax application on peteca devleopment. A total of eight treatment units, each containing $\approx 40$ fruits was used. Each of the two units then was brushed as follows: a) control-untreated; b) $1 \times 30 \mathrm{see}$; c) $2 \times 30 \mathrm{see}$; and d) $3 \times 30$ sec. Fruit in half of these treatment units were then dipped in Britseal wax (as in Expt. 1) and the remainder left untreated.

Fruit injury was assessed as described above. Data were tested by analysis of variance as a $2 \times 4$ factorial replicated three times.

Ethylene, waxing, and delays (Expt. 3). Eight treatment units were prepared, each containing 40 lemons. The following treatment regimes were then applied: a) control-untreated; b) wax applied as soon as possible after fruit arrived at the laboratory; c) fruit degreened $(50 \mu \mathrm{l}$ ethylene/liter at $25 \mathrm{C}$ for 3 days) followed by wax; d) fruit stored for 3 days at the same temperature (25C) as treatment $\mathrm{C}$ and then waxed; e) fruit degreened, stored for 5 days at 20C, and then waxed; f) stored for 5 days at $20 \mathrm{C}$, degreened, and then waxed; g) fruit degreened, stored for 10 days at $20 \mathrm{C}$, and then waxed; and $\mathrm{h}$ ) stored for 10 days at 20C, degreened, and then waxed.

The fruit were then stored under ambient conditions, 15 to $28 \mathrm{C}$.

The fruit were examined 5 days after the last treatment was applied (18 days from the beginning of the experiment) and peteca development assessed. The data were transformed using a square-root transformation, and significant treatment differences were determined using an analysis of variance. The experiment was replicated three times. LSD values at $P=0.05$ were. then used to determine significant differences among means. 
Table 3. Analysis of variance of the effects of brushing and waxing on peteca development in 'Mcyer' lemons. Data in Fig. 2.

\begin{tabular}{lrcc}
\hline \hline Source & df & $\begin{array}{c}\text { Mean } \\
\text { squarcs }\end{array}$ & $\mathrm{F}$ \\
\hline Wax & 1 & 5.23 & $155.0^{* * *}$ \\
Brushing & 3 & 0.77 & $22.7^{* * *}$ \\
Wax $\times$ brushing & 3 & 0.11 & $3.4^{*}$ \\
Poolcd residual & 16 & 0.03 & \\
\hline
\end{tabular}

$*, * * * P<0.05$ and 0.001 , respectively.

Table 4. Effect of ethylene degreening and delaying wax application on petcca development in Icmons.

\begin{tabular}{lc}
\hline \hline Treatment & $\begin{array}{c}\text { Peteca rind } \\
\text { injury index }\end{array}$ \\
\hline Control--untreated & $0.2 \mathrm{a}^{\mathrm{z}}$ \\
Waxed immediately & $1.7 \mathrm{c}$ \\
Degrcened and waxed & $0.5 \mathrm{~b}$ \\
Stored 3 days and waxed & $0.7 \mathrm{~b}$ \\
Degreened, stored 5 days, and waxed & $0.2 \mathrm{a}$ \\
Stored 5 days, degreened, and waxed & $0.5 \mathrm{~b}$ \\
Degrecned, stored 10 days, and waxed & $0.3 \mathrm{ab}$ \\
Storcd 10 days, degrcened, and waxed & $0.5 \mathrm{~b}$ \\
\hline
\end{tabular}

${ }^{\mathrm{z}}$ Mean scparation by LSD, $P<0.05$.

Table 5. Analysis of variance of the effects of waxing, temperature, and their interaction on peteca development in 'Meyer' lemons.

\begin{tabular}{lrcc}
\hline \hline & \multicolumn{3}{c}{ Mean } \\
Source & df & squares & $F$ \\
\hline Waxing & 2 & 0.68 & $21.7^{* * *}$ \\
Temperaturc (temp) & 3 & 0.05 & $1.7^{\text {NS }}$ \\
Waxing $\times$ temp & 6 & 0.08 & $2.6^{*}$ \\
Pooled residual & 24 & 0.03 & \\
\hline
\end{tabular}

Ns,****Not significant at $P>0.05$ or significant at $P<0.05$ or 0.001 , respectively.

Waxing and storage temperature (Expt 4). The effect of fruit storage temperatures and wax types on peteca development was studied in a $3 \times 4$ factorial experiment conducted early in 1989 . Twelve treatment units were prepared, each containing 40 fruit. These were divided into three groups of four and one of the following wax treatments was applied by dipping: a) control-water only; b) carnauba wax emulsion-16\% solids (Technimul, Dusseck Campbell, Sydney, Australia); and c) polyethylene wax emulsion$16 \%$ solids (Britseal, Milestone Chemical, Melbourne, Australia).

The four treatment units receiving each wax treatment were then stored 12 days at $10,15,20$, or $25 \mathrm{C}$.

After this period, fruit were examined for peteca development. The experiment was replicated three times.

Expt. 1. There was no significant effect of the fungicide guazatine on peteca development and there was also no interaction between this treatment and the other factors tested (Table 1). The application of wax, however, to nondegreened fruit significantly increased peteca incidence $(P<0.01$, Table $2)$. There was a significant interaction be-

Table 6. Rind injury index values for peteca development in 'Meyer' lemons when treated with two types of waxes and stored for 12 days at various constant temperatures.

\begin{tabular}{lccccc}
\hline & \multicolumn{4}{c}{ Peteca development } \\
\cline { 2 - 5 } & \multicolumn{4}{c}{ Temp $\left({ }^{2} \mathrm{C}\right)$} \\
Wax & 10 & 15 & 20 & 25 & Mean \\
\hline None & $0.35^{y}$ & 0.34 & 0.20 & 0.30 & 0.30 \\
Carnauba & 0.57 & 0.39 & 0.50 & 0.75 & 0.55 \\
Polyethylenc & 1.02 & 0.67 & 0.88 & 0.54 & 0.78 \\
\hline
\end{tabular}

${ }^{2}$ Rind injury index

Mean scparation by LSD, $P<0.05$.

tween wax and ethylene degreening, so that degreening fruit before waxing significantly reduced the wax effect $(P<0.01)$ and they developed no more peteca than the control (Table 2).

Expt. 2. Wax application had a highly significant effect on peteca development, irrespective of brushing time $(P<0.001)$ (Table 3 ). Brushing was also significant in increasing peteca incidence $(P<0.001$, Fig. 2$)$.

There was also a significant interaction between brushing and wax $(P<0.05)$, with the highest incidence of peteca occurring when fruit were brushed two or more times (60 or 90 see) and waxed.

Expt. 3. The highest incidence of peteca occurred when fruit were waxed immediately upon arrival at the laboratory (Table 4). Delaying wax application for as little as 3 days after arrival at the laboratory significantly reduced peteca development when compared to early waxing of fruit and was as effective as 3 days degreening before waxing. Ethylene degreening was only slightly beneficial in reducing peteca incidence when applied before the 5-day storage regime ( $P$ $<0.05)$. Storage of up to 10 days, with and without degreening, did not reduce peteca any more than the 3-day storage period before wax was applied.

Expt. 4. Storage temperature did not significantly affect peteca development $(P=$ 0.20 ), but there was a significant effect of waxing $(P=0.001)$ and a significant wax $\mathbf{x}$ temperature interaction $(P=0.04$, Table $5)$. Both waxes increased peteca, but the carnauba-based formulation tended to produce less, particularly at $20 \mathrm{C}$ and below.

The development of peteca during the postharvest handling of 'Meyer' lemons confirms observations by Oberbacher and Knorr (1965) that this disorder not only occurs in the orchard but also during storage. This work, however, shows that wax application greatly enhanced the incidence and severity of the disorder. Reasons for the response are unclear, but it could be due to physiological stress produced by increased $\mathrm{CO}_{2}$ concentrations associated with wax application (Hasegawa and Iba, 1980; Vines et al., 1968). This increased $\mathrm{CO}_{2}$ concentration increased organic acid content (Young and Biale, 1968) and affected $\mathrm{Ca}$ availability (Khalidy et al., 1969). This enhanced availability may be a major factor in peteca development (Khalidy et al., 1969).
Delaying wax application for at least 3 days after fruit harvest greatly reduced susceptibility; thus, if peteca development becomes a problem early in the season, fruit should be stored for 3 to 4 days before being waxed. Brushing times should be kept to a minimum during fruit movements along the packing line and, if practicable, carnaubabased waxes should be used.

The fungicide guazatine, which induces a rind burn on lemons when applied at high concentrations (unpublished data), had no influence on peteca development.

\section{Literature Cited}

Chapot, H. and H. Bachcecioglu. 1969. Some lemon culture troubles in Turkey. Proc. First Intl. Citrus Sym. 3:1279-1283.

Fawcett, H.S. and H.A. Lee. 1926. External spots, markings and eruptions, p. 440-524. In: C.V. Piper (cd.). Citrus diseases and their control. McGraw-Hill, New York.

Grierson, W. 1981. Physiological disorders of citrus fruits. Proc. Intl. Soc. Citricult, 2:764-767.

Hall, E. G., D. Leggo, and J.A. Seberry. 1968. Ethylene degreening of citrus fruit. Agr. Gazette of N.S. W. 79:721-728.

Hasegawa, Y. and Y. Iba. 1980. The effects of coating with wax on citrus fruit. Bul. Fruit Tree Res. Sta. 7:85-97.

Khalidy, R., A. Jamali, and H. Bolkan. 1969, Causes of peteca disease of lemons as occurring in Lebanon. Proc. First Intl. Citrus Sym. 3:12531261.

Knorr, L.C. 1963. Rumple, a ncw disease of lemon fruits. Plant Dis. Rptr. 47:335-339.

Knorr, L.C. and R.C.J. Koo. 1969. Rumple-A serious rind collapse of lemons in Florida and in Mediterranean countries. Proc. First Intl. Citrus Sym. 3:1463-1472.

Oberbacher, M.F. and L.C. Knorr. 1965. Increase of rumple and decay in lemon fruit during storage. Proc. Amer. Soc. Hort. Sci. 86:260-266.

Offers, J.A. 1987. Defects. In: Citrus diseases and defects found in the marketplace. Licenced Citrus Survey and Consulting Bureau Publications, Papendrecht, The Netherlands. p. 41.

Salerno, M. 1963. H "raggrinzimento dells buccia:" grave alterazionc dei frutti di limone. Tecnica Agr. 15:507-511.

Vines, H. M., W. Grierson, and G.J. Edwards. 1968. Respiration, internal atmosphere and ethylene evolution of citrus fruit. Proc. Amer. Soc. Hort. Sci. 92:227-234.

Young, R.E. and J.B. Biale. 1968. Carbon dioxide effects on fruits III. The fixation of $\mathrm{C}^{14} \mathrm{O}$ in lemon in an atmosphere enriched with carbon dioxide. Planta (Bcrl.). 81:253-263. 